\title{
Endoscopic vacuum-assisted therapy of infected pancreatic pseudocyst using a coated sponge
}

Endoscopic vacuum-assisted therapy (EVAT) is a reliable treatment for endoscopically accessible abscesses and was recently described in the management of infected pancreatic pseudocyst (IPC) [1 4].

EVAT when performed in the region of the celiac trunk und portal venous system has, in theory, a higher risk of bleeding than when performed in other regions of the body. We treated a woman who had sepsis due to an IPC, chronic pancreatitis, and pronounced gastric varices by EVAT, but with a coated sponge.

The treatment was generally performed as previously described [4]. After 1 week of endoscopic therapy the cyst was free of necrosis and we started EVAT. We adjusted the size of the sponge according to the local topography and wrapped the Endo-SPONGE (B. Braun, Melsungen, Germany) in one layer of Suprasorb CNP Drainage Film (Lohmann \& Rauscher, Vienna, Austria), a double-layered film for vacuum therapy of wounds ( $\bullet$ Fig. 1 and - Fig. 2) [5]. This set is not commercially available. Secretions were continuously evacuated with a suction of $120 \mathrm{~mm} \mathrm{Hg}$ $(16 \mathrm{kPa})$. We replaced the coated EndoSPONGE system on the third day and finished EVAT on the seventh day.

The extraction of the wrapped EndoSPONGE-system was, compared with the extraction of a pure sponge, easier, with less pulling force ( Fig. 3 ). The transgastric access into the cyst was also smoother and less bloody ( $\bullet$ Fig.4). On the seventh day of EVAT the pseudocyst was resolved. Finally we closed the gastrocystic fistula with metallic clips and one Endoloop (Olympus, Tokyo, Japan) ( $\bullet$ Fig. 5).

No complications occurred during therapy and within 6 months after therapy. The treatment of IPC was completed during a single hospital stay.

In our opinion the coated sponge is an improvement in EVAT of infected pancreatic pseudocyst, because it simplifies the extraction of the Endo-SPONGE system and reduces the bleeding risk.

Endoscopy_UCTN_Code_TTT_1AS_2AD

Competing interests: None

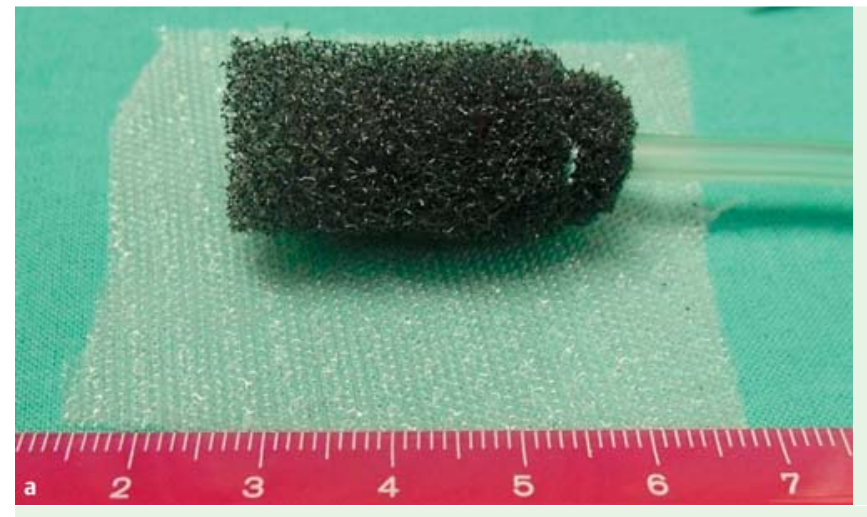

Fig. 1 a Endo-SPONGE adjusted to a size of $35 \mathrm{~mm}$ in length and $14 \mathrm{~mm}$ in diameter. Beneath the EndoSPONGE lies Suprasorb CNP Drainage Film. b Suprasorb Drainage Film wrapped around the Endo-SPONGE and fixed by sutures. A guide wire is inside the suction tube.

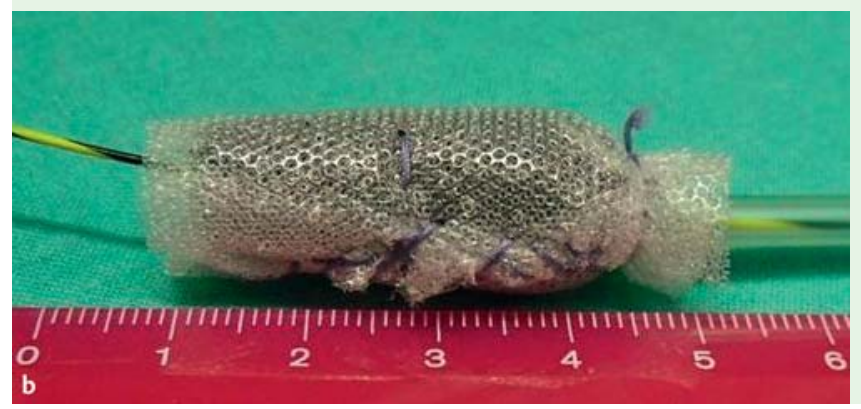

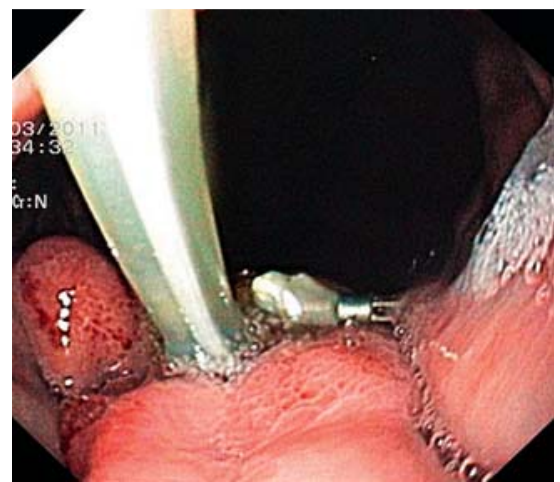

Fig. 2 Endoscopic image of the coated EndoSPONGE localized in the gastrocystic fistula.

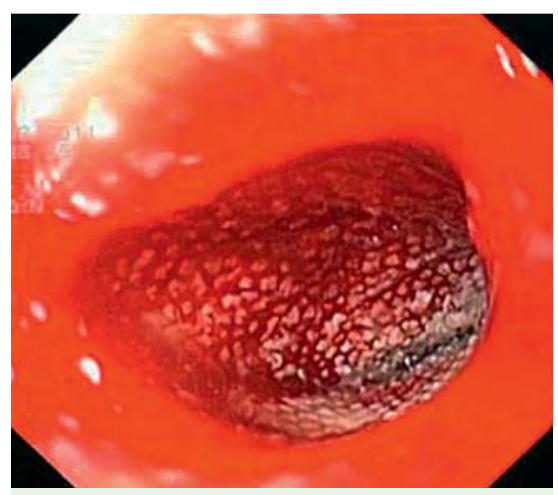

Fig. 4 Endoscopic view of the gastrocystic fistula on the seventh day of EVAT with coated sponge.

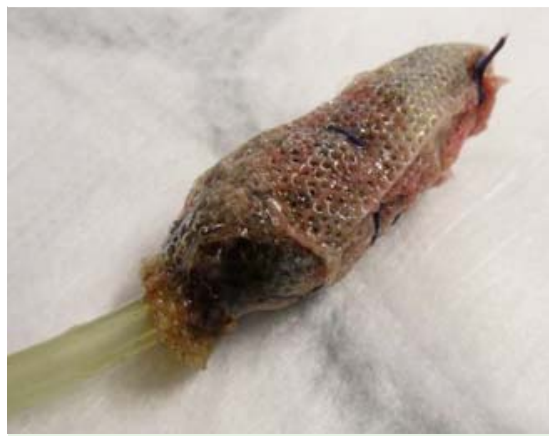

Fig.3 Image of the extracted Endo-SPONGE wrapped in one layer of Suprasorb CNP Drainage Film.

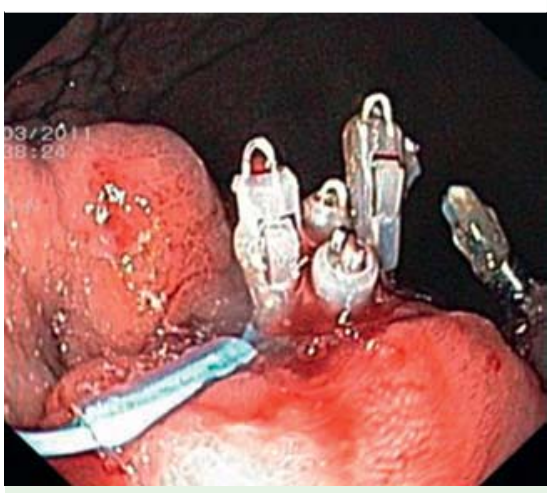

Fig. 5 Endoscopic view of the gastrocystic fistula closed by metallic clips and one Endoloop on the seventh day of EVAT. 


\section{Wallstabe, A. Tiedemann, I. Schiefke}

Department of Gastroenterology and Hepatology, Klinikum St. Georg, Leipzig, Germany

\section{References}

1 Wedemeyer J, Schneider A, Manns MP et al. Endoscopic vacuum-assisted closure of upper intestinal anastomotic leaks. Gastrointest Endosc 2008; 67: 708 - 711

2 Wallstabe I, Plato R, Weimann A. Endoluminal vacuum therapy for anastomotic insufficiency after gastrectomy. Endoscopy 2010; 42: E165-E166
3 Loske G, Schorsch T, Müller C. Intraluminal and intracavitary vacuum therapy for esophageal leakage: a new endoscopic minimally invasive approach. Endoscopy 2011; 43: $540-544$

4 Wallstabe I, Tiedemann A, Schiefke I. Endoscopic vacuum-assisted therapy of an infected pancreatic pseudocyst. Endoscopy 2011; 43: E312 -E313

5 Reich-Weinberger S, Schmitz M, Öfner D. New ways in the treatment of the "open abdomen" with a new device and the controlled negative pressure. Journal of Wound Technology 2011; 11: $32-34$
Bibliography

DOI http://dx.doi.org/

10.1055/s-0031-1291525

Endoscopy 2012; 44: E49-E50

(c) Georg Thieme Verlag KC

Stuttgart · New York

ISSN 0013-726X

\section{Corresponding author}

\section{Wallstabe, MD}

Department of Gastroenterology and Hepatology Klinikum St. Georg

Delitzscher Straße 141

04129 Leipzig

Germany

Fax: +49-341-9092673

wallstabe@endoskopieren.de 